\begin{tabular}{|ll|}
\hline Received & $:$ 10 Agustus 2020 \\
Revised & $:$ 13 Desember 2020 \\
Accepted & $:$ 14 Desember 2020 \\
Online & $:$ 15 Desember 2020 \\
Published & $:$ 18 Desember 2020 \\
\hline
\end{tabular}

\title{
Ekosistem Mangrove Binuangeun, Banten: Kondisi Fisik Dan Kimia Serta Ragam Ikan
}

\author{
Fitri Andriyani $^{1, a)}$, Lintang Anindhitya Indraswari ${ }^{1}$, Ade Suryanda ${ }^{1}$ \\ ${ }^{1}$ Pendidikan Biologi, Fakultas MIPA, Universitas Negeri Jakarta \\ $凶:{ }^{\text {a) }}$ fitriandriyani_1304618003@mhs.unj.ac.id
}

\begin{abstract}
Binuangeun Mangrove Ecosystem is located in the south western Java Island, in the area of Lebak Regency, Banten Province. Mangrove ecosystems are ecosystems that located at the Coastal areas which are a habitat for a variety of marine animals which are associated with it, mostly fish, because of its complex or a very effective root structure which can provide a place for fish to be able to live, take shelter, develop, breed and also look for food. This research was conducted to determine the physical and chemical condition and the variety of fishes which found in the Binuangeu, Banten Mangrove Ecosystem. This research method uses literature study. Physical and chemical conditions of the Binuangeun Mangrove Ecosystem, Banten have degrees of temperature ranging from 28.20 32.20; acidity range between 7.00 - 8.09; turbidity ranges from 22.50 - $76.00 \mathrm{NTU}$; water current ranged from 0.079 to 0.189 ; phosphate content ranges from $0.02-0.008$; salinity ranges from 30-35 PSU; and dissolved oxygen content ranges from 5.67 - 8.70. The types of fish found in the Binuangeun Mangrove Ecosystem, Banten are 45 species from 22 Family. The most abundant and relatively high species of existence is the Gobiidae with 10 species.
\end{abstract}

Keywords: Banten, Binuangeun, Ecosystems, Fish, Mangroves

\begin{abstract}
Abstrak
Ekosistem Mangrove Binuangeun terletak di Selatan Pulau Jawa bagian barat, di wilayah Kabupaten Lebak, Provinsi Banten. Ekosistem mangrove merupakan ekosistem yang terletak di wilayah pesisir yang menjadi habitat bagi berbagai macam hewan laut yang berasosiasi dengannya, terutama ikan, hal tersebut adanya struktur akar yang kompleks atau sangat efektif dan unik yang dapat memberi tempat untuk ikan-ikan agar dapat hidup, berlindung, berkembang biak dan juga mencari makan. Penelitian ini dilakukan dengan tujuan untuk mengetahui ekosistem mangrove melalui kondisi fisik dan kimia serta ragam ikan yang terdapat di ekosistem Binuangeun, Banten. Metode penelitian ini menggunakan studi literatur. Kondisi fisik dan kimia Ekosistem Mangrove Binuangeun, Banten memiliki derajat suhu berkisar antara 28,20 - 32,20; derajat keasaman berkisar antara 7,00 - 8,09; kekeruhan berkisar antara 22,50 - 76,00 NTU; kuat arus air berkisar antara 0,079-0,189; kandungan fosfat berkisar antara 0,02-0,008; salinitas berkisar antara $30-35$ PSU; dan kandungan oksigen terlarut berkisar antara 5,67 - 8,70. Jenis ikan yang terdapat pada Ekosistem Mangrove Binuangeun, Banten adalah 45 spesies dari 22 suku. Spesies yang paling berlimpah dan relatif tinggi keberadaannya yakni Suku Gobiidae dengan 10 spesies.
\end{abstract}

Kata Kunci: Banten, Binuangeun, Ekosistem, Ikan, Mangrove 


\section{PENDAHULUAN}

Ekosistem mangrove merupakan ekosistem yang terletak di wilayah pesisir yang menjadi habitat bagi berbagai macam hewan laut yang berasosiasi dengannya, terutama ikan. Banyaknya spesies ikan yang terdapat di ekosistem mangrove disebabkan oleh adanya struktur akar yang kompleks atau sangat efektif dan unik yang dapat memberi tempat untuk ikan-ikan agar dapat hidup, berlindung, berkembang biak dan juga mecari makan (Barbier EB et al., 2011; Kholis et al., 2019; Nagelkerken et al., 2008; Ochiewo et al., 2012). Perakaran mangrove dapat meredam gelombang laut, sehingga air yang berada di sekitarnya cenderung lebih tenang (Milchakova, 2003; Wang et al., 2009), kondisi tersebut menunjukkan fungsi dari ekosistem mangrove yaitu, dapat dijadikan sebagai feeding ground, nursery ground, spawning ground bagi banyak organisme akuatik, terutama ikan (Bangen, 2004). Hal tersebut, memungkinkan banyaknya ragam ikan yang berasosiasi dengan ekosistem mangrove. Ekosistem mangrove juga memiliki peran penting dalam melindungi dari abrasi dan mencegah terjadinya intrusi air laut. Ekosistem mangrove juga dapat berperan dalam membersihkan zat-zat polutan.

Luas ekosistem mangrove di Indonesia mencapai sekitar 23\% dari luas ekosistem bakau di dunia (Sitorus et al., 2017)7). Pada masa sekarang ini, banyak ekosistem mangrove di Indonesia yang mengalami kerusakan. Total wilayah ekosistem mangrove yang terdapat di Indonesia adalah sekitar 8,5 juta hektar, tetapi yang berada dalam keadaan baik hanya sekitar 3,6 juta hektar. Kerusakan ekosistem mangrove seringkali disebabkan oleh pembukaan lahan tambak atau area budidaya air payau, penebangan bakau, dan abrasi yang terjadi di sepanjang pesisir (Descasari et al., 2016; Fitriana, 2006; Sitorus et al., 2017).

Perkembangan ekosistem mangrove tidak terlepas dari pengaruh pasang surut air laut dan juga jenis substrat yang ada pada konsisi fisik serta kimia di lingkungan tersebut (Rahman, 2010). Mangrove memiliki peranan besar terhadap siklus kehidupan biota laut dan berperan penting dalam melindungi pantai dari gelombang, angin dan badai. Tegakan mangrove dapat melindungi pemukiman, bangunan dan pertanian dari angin kencang atau intrusi air laut (Atmoko, Tri. Sidiyasa, 2007). Penelitian ini diperlukan karena Indonesia adalah salah satu negara kepulauan terbesar di dunia yang memiliki potensi sumberdaya pesisir dan lautan yang sangat besar (Martuti, Nana Karida, et al. 2019). Sebagai negara kepulauan, diperlukan adanya analisis kondisi fisik dan kimia yang dilakukan pada beberapa ekosistem mangrove agar para ilmuwan dapat mengelola kondisi pulau yang ada dari berbagai ancaman dan juga tantangan pengelolaan ekosistem mangrove di wilayah Binuangeun, Banten.

Sehubungan dengan banyaknya kerusakan ekosistem mangrove yang terjadi dan struktur ekosistem mangrove yang dapat mendukung berbagai macam ikan untuk hidup di dalamnya, maka perlu dilakukan penelitian untuk mengetahui kondisi fisik dan kimia ekosistem mangrove serta ragam ikan khususnya di Ekosistem Mangrove Binuangeun yang terletak di Selatan Pulau Jawa bagian barat, terletak di wilayah Kabupaten Lebak, Provinsi Banten. Hasil penelitian ini selanjutnya dapat dijadikan informasi dasar dalam konservasi Ekosistem Mangrove Binuangeun,Banten agar pemanfaatannya dapat dilakukan secara berkelanjutan dengan tetap memperhatikan kelestarian ekosistem dan sumber daya, terutama ikan yang berada di dalamnya. Tujuan dari penelitian ini adalah untuk mengetahui ekosistem mangrove melalui kondisi fisik dan kimia serta ragam ikan yang terdapat di ekosistem Binuangeun, Banten. 


\section{METODE}

Studi ini dilaksanakan pada tahun 2020, dimana lokasi penelitian ditentukan berdasarkan keberadaan ekosistem mangrove di kawasan Binuangeun, Banten. Studi ilmiah ini dilaksanakan dengan teknis kajian pustaka (literature study). Data yang diperoleh berupa data sekunder yang berasal dari resmi berupa artikel jurnal, tulisan-tulisan ilmiah resmi baik dari lembaga maupun dari pemerintah baik dalam bentuk buku maupun digital. Data yang diperoleh dikompilasi, dianalisis, dan disimpulkan sehingga mendapatkan hasil yang komprehensif mengenai kondisi fisik dan kimia beserta ragam ikan pada Ekosistem Mangrove, Binuangeun, Banten. Penelitian ini menggunakan metode analisis deskriptif untuk menganalisis, menggambarkan, dan meringkas berbagai kondisi, situasi fisik dan kimia data yang telah dikumpulkan dari hasil hasil kajian literatur.



Gambar. Peta Binuangen, Banten dengan Skala 1:2.500.000 dengan titik koordinat $6.842401665619124,105.90113192882743$

Sumber: Google Inc. (2020)

\section{HASIL DAN PEMBAHASAN}

\section{Kondisi Fisik dan Kimia Ekosistem Mangrove Binuangeun, Banten}

Melalui penelusuran literatur yang telah dilakukan, didapatkan data mengenai kondisi fisik dan kimia Ekosistem Mangrove Binuangeun, Banten. Parameter kondisi fisik dan kimia yang didapatkan datanya yaitu, derajat keasaman atau $\mathrm{pH}$, suhu, fosfat, kadar oksigen terlarut (DO), kuat arus air, salinitas, dan kekeruhan.

Tabel 1. Data Parameter Fisik dan Kimia Ekosistem Mangrove Binuangeun, Banten

\begin{tabular}{ccccccc}
\hline $\mathrm{T}$ & $\mathrm{pH}$ & Kekeruhan & Arus Air $(\mathrm{m} / \mathrm{s})$ & Fosfat & Salinitas & DO \\
$\left({ }^{\circ} \mathrm{C}\right)$ & & $(\mathrm{NTU})$ & & $(\mathrm{mg} / \mathrm{L})$ & $(\mathrm{PSU})$ & $(\mathrm{mg} / \mathrm{L})$ \\
\hline $28,20-32,20$ & $7,00-8,09$ & $22,50-76,00$ & $0,079-0,189$ & $0,02-0,08$ & $30-35$ & $5,67-8,70$
\end{tabular}

Sumber : (Patty et al., 2015; Rahman, 2010; Sukardjo, 2004; Zulfikar, 2018)

Kondisi Fisik dan Kimia Ekosistem Mangrove Binuangeun, Banten pada data yang didapatkan yakni suhu, $\mathrm{pH}$, kekeruhan, arus air, fosfat, salinitas, dan DO (Dissolved Oxygen).

$\underline{\text { Suhu }}$ 
Kondisi suhu pada ekosistem mangrove Binuangeun, Banten menujukkan nilai yang relatif berkisar antara $28,20^{\circ} \mathrm{C}-32,20^{\circ} \mathrm{C}$ (Tabel 1). Pasang surut membuat adanya perbedaan suhu karena dipengaruhi oleh cuaca, kedalaman dan juga waktu pengambilan sampel yang berbeda-beda (Rahman, 2010).

Suhu pada perairan di wilayah ekosistem mangrove Binuangeun sangatlah penting terhadap kehidupan biota seperti ikan. Umumnya dengan kenaikan suhu, laju metabolisme akan meningkat (Descasari et al., 2016). Pertumbuhan mangrove yang baik memerlukan suhu udara minimal lebih besar dari $20^{\circ} \mathrm{C}$ dan perbedaan suhu musiman tidak melebihi $5^{\circ} \mathrm{C}$ (Kumana, 2015; Pamoengkas, 2003).

Derajat Keasaman $(\mathrm{pH})$

Pengukran $\mathrm{pH}$ pada ekositem Mangrove Binuangeun menunjukkan angka berkisar antara 7,00 - 8,09 (Tabel 1). Derajat keasaman (pH) akan mempengaruhi daya tahan organisme dan reaksi enzimatik. Berdasarkan Keputusan Menteri Negara Lingkungan Hidup KEP No.51/MNLH/I/2004, kisaran pH tersebut masih memenuhi baku mutu untuk kelangsungan hidup biota laut, dengan baku mutu yang disarankan berkisar antara 7- 8,50 (Rahman, 2010).

Kekeruhan

Kekeruhan merupakan gambaran dari seberapa jernihnya suatu perairan. Perairan dengan kekeruhan yang tinggi dan kecerahan yang rendah menyebabkan penetrasi cahaya akan terganggu hingga berdampak terbatasnya produktivitas perairan (Nybakken, 1988). Baku mutu yang disarankan menurut Keputusan Menteri Negara Lingkungan Hidup KEP No.51/MNLH///2004, adalah tidak melebihi kadar 5 NTU. Sedangkan tingkat kekeruhan di perairan ekosistem mangrove Binuangeun berkisar antara 22,50-76,00 NTU yang menandakan kekeruhan ini telah melampaui baku mutu kekeruhan untuk biota laut seperti ikan.

Arus Air

Arus adalah gerakan mengalir suatu massa air yang disebabkan oleh tiupan angin, perbedaan densitas, atau pergerakan gelombang panjang(Daruwedho et al., 2016). Kecepatan air pada ekosistem mangrove di Binuangeun berkisar antara 0,079 $0,189 \mathrm{~m} / \mathrm{s}$. Pergerakan pasang surut air akan berdampak pada bentuk morfologi dasar dari suatu perairan. Seperti perairan yang arus pasang surutnya cepat maka dapat mengendapkan sedimen pasir dan sedimentasinya cukup rendah (Rahman, 2010).

Fosfat

Kadar fosfat pada ekosistem mangrove berkisar antara 0,02-0,08 mg/L. Baku mutu konsentrasi fosfat yang layak untuk kehidupan biota laut dalam Keputusan Menteri Lingkungan Hidup, KLH (2004) adalah 0,015 mg/L. Data hasil penelitian menunjukkan bahwa kadar fosfat di perairan ekosistem ini berada di batas atas konsentrasi yag dipersyaratkan. Tingkat kesuburan perairan yang cukup subur berdasarkan kadar fosfat berkisar antara 0,0021- 0,050 mg/l (Wardoyo, 1982).

$\underline{\text { Salinitas }}$

Salinitas pada perairan ekosistem mangrove Binungeun berkisar antara 30-35 PSU. Vegetasi mangrove dapat bertahan dan mampu hidup dengan subur pada kisaran salinitas antara 10-30 PSU, salinitas sangat penting bagi ketahanan, pertumbuhan serta zonasi mangrove (Aksornkoae, 1993). Berdasarkan data penelitian pada tabel 1, maka didapatkan hasil bahwa kondisi salinitas pada perairan ekosistem mangrove di Binuageun melebihi kadar toleransi.

Oksigen Terlarut (DO/Dissolved Oxygen)

Pengukuran DO berdasarkan tabel 1 didapatkan hasil berkisar antara 5, 67 8,70 mg/L. Berdasarkan kadar DO normal berkisar 5,7-8,5 mg/L maka kadar DO pada 
ekosistem mangrove di Binuangeun dapat dikatakan normal (Rahman, 2010). Batas kadar DO yang mematikan berbeda-beda tergantung pada jenis, kesehatan, dan stadia biota serta faktor-faktor lingkungan lainnya (Pamoengkas, 2003).

\section{Ragam Ikan Pada Ekosistem Mangrove Binuangeun, Banten}

Melalui penelusuran literatur yang telah dilakukan, didapatkan data kemungkinan ragam ikan yang dapat ditemukan di Ekosistem Mangrove Binuangeun, Banten. Ragam Ikan pada Ekosistem Mangrove Binuangeun, Banten dapat dilihat pada Tabel 2 berikut:

Tabel 2. Data Ragam Ikan di Ekosistem Mangrove Binuangeun, Banten

\begin{tabular}{|c|c|c|c|}
\hline $\begin{array}{l}\text { No. } \\
\text { Suku }\end{array}$ & Suku & $\begin{array}{c}\text { No. } \\
\text { Jenis }\end{array}$ & Jenis \\
\hline 1. & Acanthuridae & 1. & Acanthurus blochii \\
\hline 2. & Adrianichthyidae & 2. & Oryzias javanicus \\
\hline 3. & Ambassidae & 3. & Ambassis gymnocephalus \\
\hline 4. & Antennariidae & 4. & Antennarius sp. \\
\hline \multirow[t]{2}{*}{5.} & & 5. & Apogon hyalosoma \\
\hline & & 6. & Nectamia fusca \\
\hline 6. & Atherinidae & 7. & Atherinomorus lacunosus \\
\hline \multirow[t]{3}{*}{7.} & & 8. & Istiblennius dussumieri \\
\hline & Blenniidae & 9. & Istiblennius edentulus \\
\hline & & 10. & Salarias sp. \\
\hline \multirow[t]{2}{*}{8.} & & 11. & Chaetodon auriga \\
\hline & 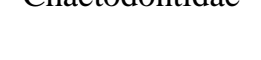 & 12. & Chaetodon melannotus \\
\hline 9. & Elopidae & 13. & Elops hawaiensis \\
\hline \multirow[t]{2}{*}{10.} & & 14. & Stolephorus indicus \\
\hline & & 15. & Thryssa mystax \\
\hline 11. & Gerreidae & 16. & Gerres oyena \\
\hline \multirow[t]{5}{*}{12.} & & 17. & Acentrogobius caninus \\
\hline & & 18. & Acentrogobius nebulosus \\
\hline & Gobiidae & 19. & Amblygobius stethophthalmus \\
\hline & & 20. & Asterropteryx semipunctata \\
\hline & & 21. & Bathygobius cocosensis \\
\hline
\end{tabular}




\begin{tabular}{|c|c|c|c|}
\hline & & 22. & Glossogobius biocellatus \\
\hline & & 23. & Gnatholepis cauerensis \\
\hline & & 24. & Istigobius ornatus \\
\hline & & 25. & Pandaka sp. \\
\hline & & 26. & Periophthalmus sp. \\
\hline & & 27. & Pseudogobius javanicus \\
\hline 13. & & 28. & Halichoeres argus \\
\hline & & 29. & Halichoeres chloropterus \\
\hline & Labridae & 30 . & Halichoeres marginatus \\
\hline & & 31. & Halichoeres miniatus \\
\hline 14. & & 32. & Leiognathus decorus \\
\hline & Leiognathidae & 33. & Leiognathus equulus \\
\hline & & 34. & Leiognathus splendens \\
\hline 15. & Mugilidae & 35. & Moolgarda sp. \\
\hline 16. & & 36. & Abudefduf septemfasciatus \\
\hline & Pomacentridae & 37. & Chrysiptera glauca \\
\hline & & 38. & Chrysiptera unimaculata \\
\hline 17. & Scatophagidae & 39. & Scatophagus argus \\
\hline 18. & Sciaenidae & 40. & Pennahia argentata \\
\hline 19. & & 41. & Scorpaenodes sp. \\
\hline & & 42. & Scorpaenopsis sp. \\
\hline 20. & Sillaginidae & 43. & Sillago macrolepis \\
\hline 21. & Tetraodontidae & 44. & Arothron hispidus \\
\hline 22. & Terapontidae & 45. & Terapon jarbua \\
\hline
\end{tabular}

Sumber: (Ainullah et al., 2015; Kholis et al., 2019; Sukardjo, 2004; Wahyudewantoro, 2009; Wang et al., 2009).

Secara keseluruhan, jenis ikan yang terdapat pada Ekosistem Mangrove Binuangeun, Banten adalah 45 spesies dari 22 suku. Spesies yang paling berlimpah dan relatif tinggi keberadaannya yakni Suku Gobiidae dengan 10 spesies ikan. Semua spesies ikan yang terdapat di Ekosistem Mangrove Binuangeun, Banten dapat dilihat pada tabel 2. Suku Goobidae merupakan kelompok ikan kelas Actinopterygii yang 
biasanya hidup di perairan tawar hingga laut (Kottelat, Whitten, SN, \& Wirjatmodjo, 1993).

Kondisi di ekosistem Binuangeun ini telah dikatakan baik untuk mendukung kehidupan beragam ikan karena dari hasil data yang diperoleh, menunjukkan bahwa suhu, $\mathrm{pH}$, serta Oksigen Terlarut yang cukup normal sehingga dikatakan baik sehingga dapat digunakan sebagai habitat bagi biota ikan di ekosistem ini. kondisi tersebut mendukung banyaknya ragam ikan yang berasosiasi dengan ekosistem ini, ragam ikan yang ditemukan dapat dilihat pada tabel 2. Beberapa suku yang ditemukan hidup baik di ekosistem ini yakni suku Acanthuridae, Adrianichthyidae, Ambassidae, Antennariidae, Apogonidae, Atherinidae, Blenniidae, Chaetodontidae, Elopidae, Engraulididae, Gerreidae, Gobiidae, Labridae, Leiognathidae, Mugilidae, Pomacentridae, Scatophagidae, Sciaenidae, Scorpaenidae, Sillaginidae, Tetraodontidae, Terapontidae.

Hasil dari temuan penelitian ini dapat menggambarkan bahwa kondisi fisik dan kimia yang ada di ekosistem mangrove Binuangeun, Banten dapat dijadikan sebagi tempat berkembang biak yang baik untuk beberapa jenis ikan tertentu seperti ikan Genus Goobidae, Penelitian ini dilakukan agar data yang diperoleh dapat dijadikan sebagai acuan untuk membudidayakan dan mengelola perairan serta perikanan di daerah ini.

\section{KESIMPULAN}

Kondisi fisik dan kimia di Ekosistem Mangrove Binuangeun dari data yang didapatkan yakni, kondisi suhu cukup baik untuk mendukung pertumbuhan mangrove, $\mathrm{pH}$ air yang dikatakan masih baik untuk dapat mendukung kehidupan biota laut, khususnya ikan. Tingkat kekeruhan di perairan ekosistem tersebut sangatlah buruk karena nilainya di atas ambang mutu kekeruhan. Kadar fosfat pada ekosistem ini berada diatas ambang baku mutu yang telah ditetapkan, yang menyebabkan kesuburan perairan yang tidak baik. Tingkat salinitas dikatakan cukup buruk karena telah melampaui batas toleransi tingkat salinitas yang dapat mendukung pertumbuhan subur mangrove, sedangkan kadar oksigen terlarut dikatakan normal dan baik dalam mendukung kehidupan di ekosistem tersebut. Pada Ekosistem Mangrove Binuangeun, Banten ragam ikan terdiri dari 45 spesies dari 22 suku. Spesies yang paling berlimpah dan relatif tinggi keberadaannya yakni Suku Gobiidae dengan 10 spesies. Saran untuk penelitian lanjutan yakni memperbaharui data mengenai ragam ikan yang berpotensi menjadi endemik di daerah tersebut.

\section{REFERENSI}

Ainullah, M. V., Sudarmadji, S., \& Utami, E. T. (2015). Keanekaragaman Jenis Ikan Di Blok Bedul Segoro Anak Taman Nasional Alas Purwo. Berkala Sainstek, 3(1), 1619.

Aksornkoae. (1993). Ecology and management of mangroves. IUCN.

Atmoko, Tri. Sidiyasa, K. (2007). Hutan Mangrove dan Peranannya dalam Melindungi Ekosistem Pantai. Hutan Mangrove Dan Peranannya Dalam Melindungi Ekosistem Pantai, 92-99.

Bangen. (2004). Pedoman Teknis Pengenalan dan Pengelolaan Ekosistem Mangrove. PKSPL.

Barbier EB, Hacker SD, Kennedy C, Koch EW, Stier AC, \& Silliman BR. (2011). The value of estuarine and coastal ecosystem services. Ecological Monographs, 81(2)(2), 169-193. 
Daruwedho, H., Sasmito, B., \& Amarrohman, F. (2016). Analisis Pola Arus Laut Permukaan Perairan Indonesia Dengan Menggunakan Satelit Altimetri Jason-2 Tahun 2010-2014. Jurnal Geodesi Undip, 5(2), 147-158.

Descasari, R., Setyobudiandi, I., \& Affandi, R. (2016). The relationship between mangrove ecosystem and fish diversity in Pabean Ilir and Pagirikan, Indramayu District, West Java. Bonorowo Wetlands, 6(1), 43-58. https://doi.org/10.13057/bonorowo/w060104

Fitriana, Y. R. (2006). Diversity and abundance of macrozoobenthos in mangrove rehabilitation forest in Great Garden Forest Ngurah Rai Bali. Biodiversitas, Journal of Biological Diversity, 7(1), 67-72. https://doi.org/10.13057/biodiv/d070117

Kholis, N., Patria, M. P., Soedjiarti, T., \& Suryanda, A. (2019). Composition and diversity of fish species in mangrove ecosystem at Muara Binuangeun, Lebak, Banten. Journal of Physics: Conference Series, 1402(3). https://doi.org/10.1088/1742-6596/1402/3/033065

Kumana, C. (2015). Keragaan Biofisik Ekosistem Mangrove Di Kecamatan Blrem Bayeun Dan Kecamatan Rantau Selamat, Aceh Timur. November.

Martuti, Nana Karida, et al. 2019. Ekosistem Mangrove (Keanekaragaman, Fitoremidiasi, Stok Karbon, Peran dan Pegelolaan. Lembaga Penelitian dan Pengabdian Masyarakat Universitas Negeri Padang

Milchakova. (2003). Seagrass Ecosystem. Marine Encironmental Magazine, 23-39.

Nagelkerken, I., Blaber, S. J. M., Bouillon, S., Green, P., Haywood, M., Kirton, L. G., Meynecke, J. O., Pawlik, J., Penrose, H. M., Sasekumar, A., \& Somerfield, P. J. (2008). The habitat function of mangroves for terrestrial and marine fauna: A review. Aquatic Botany, 89(2), 155-185. https://doi.org/10.1016/j.aquabot.2007.12.007

Nybakken. (1988). Suatu Pendekatan Ekologis. PT. Gramedia.

Ochiewo, J., Bosire, J., \& Okemwa, G. (2012). Mangrove linkages to coral reef and seagrass ecosystem services in Mombasa and Takaungu, Kenya - Participatory Modelling Frameworks to Understand Wellbeing Trade-offs in Coastal Ecosystem Services: Mangrove sub-component. Ecosystem Services for Poverty Allevation, $45 \mathrm{pp}$.

Pamoengkas, Y. K. H. (2003). Teknik Rehabilitasi Mangrove. In Journal Fakultas Kehutanan IPB.

Patty, S. I., Arfah, H., \& Abdul, M. S. (2015). Zat Hara (Fosfat, Nitrat), Oksigen Terlarut dan pH Kaitannya Dengan Kesuburan di Perairan Jikumerasa, Pulau Buru. Jurnal Pesisir Dan Laut Tropis, 3(1), 43. https://doi.org/10.35800/jplt.3.1.2015.9578

Rahman, A. (2010). Status Ekologi Mangrove untuk Upaya Pengelolaannya di Kawasan Pesisir Pulau Dua, Kecamatan Kasemen, Serang, Banten (di Luar Cagar Alam Pulau Dua). 97.

Sitorus, H., Lesmana, I., Tarigan, R., \& Hasan Sitorus, C. (2017). Relationship of mangrove density with fish diversity in the waters of mangrove area at Lubuk Kertang Village, Langkat District of North Sumatera. $266 \sim$ International Journal of Fisheries and Aquatic Studies, 5(5), 266-271. www.fisheriesjournal.com

Sukardjo, S. (2004). Fisheries Associated With Mangrove Ecosystem In Indonesia: A View from a Mangrove Ecologist. Biotropia, O(23), 13-39. https://doi.org/10.11598/btb.2004.0.23.201

Wahyudewantoro. (2009). Keanekaragaman Fauna Ikan Ekosistem Mangrove di Kawasan Taman Nasional Ujung Kulon, Pandeglang-Jawa Barat. Jornal Berita Biologi, 9-16. 
Wang, M., Huang, Z., Shi, F., \& Wang, W. (2009). Are vegetated areas of mangroves attractive to juvenile and small fish? The case of Dongzhaigang Bay, Hainan Island, China. Estuarine, Coastal and Shelf Science, 85(2), 208-216. https://doi.org/10.1016/j.ecss.2009.08.022

Wardoyo. (1982). Water Analysis Manual Tropical Aquatic iology Program. Biotrop, SEAMEO.

Zulfikar. (2018). Analisis Vegetasi Mangrove Pantai Binuangeun Lebak Banten. https://www.academia.edu/38331514/Analisis_Vegetasi_Mangrove_Pantai_Binuang eun_Lebak_Banten 